\title{
Effect of Amlodipine to MAP2 on Neurons Culture SH-SY5Y That Induced by Chronic Hyperglycemia
}

\author{
Shahdevi N. K., Pratama F. A., Masruroh R., Dessika R.
}

\begin{abstract}
Exposure to chronic hyperglycemia in neurons results in increased $\mathrm{Ca}^{2+}$ intracellular then causes increased oxidative stress. Oxidative stress will increase the activity of calcium activated neural protease causing MAP2 (microtubule associated protein 2) to decrease which will increase the cell death. The aim of research is to determine on the effects of amlodipine on the expression of MAP2 in SH-SY5Y neuron culture cells. This research is an experimental study, using SH-SY5Y neuron cell culture and then exposed to hyperglycemia for 6 days, then given amlodipine $10 \mathrm{nM}$ and $100 \mathrm{nM}$. Then the MAP2 expression is seen. Based on the results of the Anova test on the administration of $10 \mathrm{nM}, 100 \mathrm{nM}$ and without amlodipine on the expression of MAP2 in culture of SH-SY5 neurons, which were $50 \mathrm{mM}$ glucose for 6 days there was decrease in MAP2 (p = 0.082 ). Based on Spearman correlation test results, there was a strong relationship $(p=0.011)(r=-0.7791)$. There is decrease expression of the MAP2 after the administration of the dose of amlodipine $10 \mathrm{nM}, 100 \mathrm{nM}$ and without administration although not significant. It is estimated that another line activation occurs. One such pathway is the activation NMDA receptor will inhibit potential post synapse and increase calpain activation to cause a decrease in MAP2.
\end{abstract}

Keywords : MAP2, amlodipine, culture, SH-SY5Y, neuron.

\section{INTRODUCTION}

$\mathrm{D}$ iabetes mellitus (DM) is a group of metabolic diseases characterized by hyperglycemia due to abnormalities in damage to insulin secretion, insulin action, or both. The main causes of hyperglycemia are decreased insulin secretion and insulin action, chronic hyperglycemia with DM is associated with long-term damage, failure of various organs such as eyes, kidneys, nerves, liver, and blood vessels [1]. Diabetics are characterized by polyuria, polydipsia, polyphagia with weight loss. Diabetes mellitus in the long case can cause macrovascular and microvascular abnormalities [2]. The prevalence of diabetes mellitus in the world in the group of adults around the age of 20-79 years affects 285 million people in 2010 and there will be an increase of 439 million people in 2030. Between 2010 and

Revised Manuscript Received on January 2, 2020.

* Correspondence Author

Shahdevi N. K.*, Neurology Department, Medical Faculty of Brawijaya University, Malang, Indonesia. Email: shahdevinandar@yahoo.com

Pratama F. A., Medical Faculty of Brawijaya University, Malang, Indonesia. Email: farhanadi179@gmail.com

Masruroh R., Neurology Department, Medical Faculty of Brawijaya University, Malang, Indonesia. Email: masrurohrahayu@yahoo.com

Dessika R., Neurology Department, Medical Faculty of Brawijaya University, Malang, Indonesia. Email: dessika_dr@yahoo.com
2030 a $69 \%$ increase in predicted with diabetes mellitus in the country developing and a $20 \%$ increase in developed countries [3].

The most complications of diabetes mellitus in RSUP Dr. Cipto Mangunkusumo Jakarta (RSCM) was 54\% neuropathy in 2011 [4]. Neuropathy is damage to neurons in the nervous system and can even affect other organs. In the condition of hyperglycemia, cell metabolism will be disturbed so that cells experience interference in neutralizing free radicals during metabolic processes that cause oxidative stress. Oxidative stress can cause neuropathy. This is caused by metabolic disorders, cell signaling, cell transmission and even cell death. Increased oxidative stress will result in impaired cellular function. Increased oxidative stress causes decreased function of microtubule associated protein 2 (MAP2) so that triggers damage to the structure of microtubules in neurons and disruption of axonal transmission [5].

When hyperglycemia occurs an increase in calcium activated neural protease (calpain) due to oxidative stress and increased calcium $\left(\mathrm{Ca}^{2+}\right)$ ions [6]. Increased calcium ions $\left(\mathrm{Ca}^{2+}\right)$ will cause extracellular calcium influx, excessive calcium mobilization, limited elimination from cytoplasm [7]. Amlodipine is a calcium antagonistic drug. This drug is usually used as an antihypertensive and antiangina drug. The mechanism of action of amlodipine in nerve cells is by binding to the L-Type Calcium Channel (LTCC) receptor so that it can reduce intracellular $\left(\mathrm{Ca}^{2+}\right)$ influx. Prevention of apoptosis of cortical neuron cells exposed by high stress oxidative levels, administration of amlodipin camsylate (AC) and amlodipin besylate (BC) has been shown to have neuroprotective properties [8].

Many areas of the field of neurology are hampered by the limited choice of in vitro models that resemble adult neuron cells that express human proteins [9]. The use of primary mammalian neuron cells originating from the central nervous system embryonic tissue is limited due to the fact that, once these cells are differentiated, they can no longer be reproduced. To overcome this limitation, cell lines can be changed into neuronal cells. SH-SY5Y is one of the most commonly used [10]. The use of amlodipine in the culture of SH-SY5Y neurons exposed to chronic hyperglycemia is expected to be both a treatment and prevention so that complications do not occur, especially neuropathy. Aim this research is determine the effect of amlodipine dose of $10 \mathrm{nM}$, $100 \mathrm{nM}$ and without the administration of amlodipine on MAP2 on SH-SY5Y 
neuron cell culture that is glucose induced by $50 \mathrm{mM}$.

\section{MATERIALS AND METHODS}

Early studies using the method of pure experimental analysis in vitro in the SH-SY5Y cell culture with the approach of normality test, annova test and Spearman correlation test. The process of culture and measurement of all related parameters and morphology of neurons was carried out at the Central Laboratory of Life Sciences (LSIH) Universitas Brawijaya Malang. In this study the SH-SY5Y cell line neurons were cultured. Neuron culture was then exposed to the condition of hyperglycemia $50 \mathrm{mM}$ concentration exposed for 6 days. Then after 6 days amlodipine was given at a dose of $10 \mathrm{nM}$ and $100 \mathrm{nM}$ for 30 minutes. Then MAP2 was examined which was examined using specific antibodies by immunoflorescence. All data were processed using SPSS for Windows version 24.

\section{RESULT AND DISCUSSION}

\section{A. Effect of Amlodipine on MAP2 Expression in Hyperglycemia Conditions}

In the SH-SY5Y neuron culture model hyperglycemia (50 $\mathrm{mM}$ glucose induction) given amlodipine $10 \mathrm{nM}, 100 \mathrm{nM}$ and without amlodipin showed a decrease in MAP2 expression but not statistically significant meaning, amlodipine $10 \mathrm{nM}$ and $100 \mathrm{nM}$ could not show an increase in MAP2 expression (Figure $1 \& 2$ ). The results of this study are not in accordance with the hypothesis and the theoretical basis. This is likely in this study the induction of chronic hyperglycemia for 6 days in the culture of the SH-SY5Y neuron will increase $\left(\mathrm{Ca}^{2+}\right)$ ions in cells. This will cause the activation process of calcium dependent cellular; one type is protein phospholipase $\mathrm{C}$ and the release of arachidonic acid which will cause the process of peroxidase from lipids on cell membranes so that it can cause changing cell [11]. Giving 50 $\mathrm{mM}$ glucose induction for 6 days in neuron culture will causes increased calcium influx and oxidative stress. When neuron cells are exposed to hyperglycemia for 6 days there will be cell defense against free radicals. Various synaptic transmission activations that regulate MAP2, namely metabotropic glutamate receptors (mGluRs), mitogen-activated protein kinases (MAPKs), $\mathrm{Ca}^{2+} /$ calmodulin-dependent protein kinases (CaMKs) and protein kinase $\mathrm{C}$ (PKC) cause high phosphorylation of MAP2 so that it causes high MAP2. In this study, the high expression of MAP2 is caused by its activation process in fighting oxidative stress which is increased due to glucose induction of $50 \mathrm{mM}$ through mGluRs, MAPKs, CaMKs and PKC [12]. The administration of amlodipine as a calcium channel blocker is expected to increase the expression of MAP2 that works on LTCC (L-Typed Calcium Channel) receptors thereby reducing intracellular $\mathrm{Ca}^{2+}$ ion influx [13]. In this study showed a decrease in MAP2 expression after administration of amlodipine but not significant. This is likely and is caused by damage to the mitochondrial membrane resulting in increased intracellular $\mathrm{Ca}^{2+}$ ions due to administration of amlodipine at a dose of 10 and $100 \mathrm{nM}$. High intracellular $\mathrm{Ca}^{2+}$ ions cause dysfunction of MAP2 through the calpain pathway resulting in decreased MAP2 function.

In the Leeds study, in a study in the culture of cerebellar granule cells (CGCs), examining the dose of amlodipine 0.1-1000 nM showed that giving amlodipine at a dose of 10 $\mathrm{nM}$ was the maximum dose to restore viability of neuron cells in free radicals because the higher dose of amlodipine would result in a decrease in amlodipine dose of $10 \mathrm{nM}$ was the maximum dose to restore the viability of neuron cells in free radicals because neuron protection. Whereas the potential neuroprotective dose and to maintain apoptosis from neuron cells is best at a dose of $5 \mathrm{nM}$ [14]. So that administration of amlodipine at doses of 10 and $100 \mathrm{nM}$ can reduce MAP2 expression.
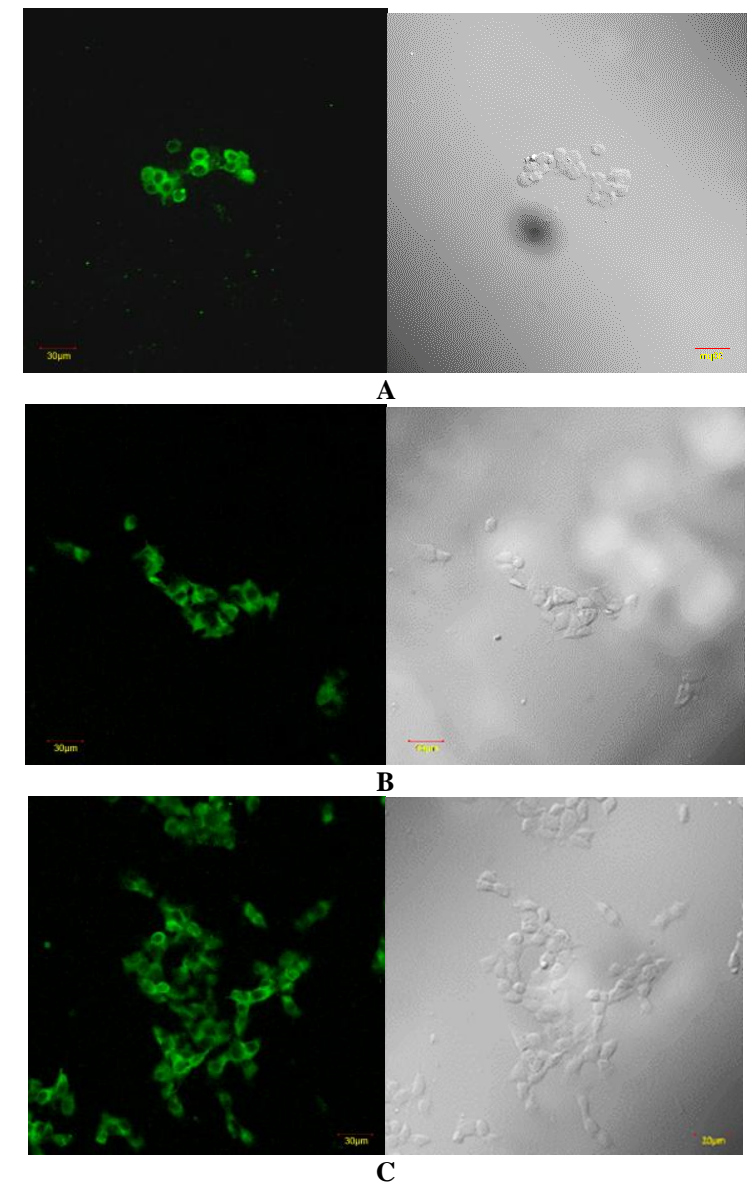

Fig 1. MAP2 expression in neuron culture by treatment of hyperglycemia $(50 \mathrm{mM})$.

In figure 1, A without the administration of amlodipine, picture $B$ is treated with amlodipine $10 \mathrm{nM}$ and $\mathrm{C}$ is given amlodipine $100 \mathrm{nM}$. Left green picture with fluorescein isothiocyanate (FITC), right grey picture without differential interference contrast (DIC) (culture $6^{\text {th }}$ day, MAP2, 400x magnification).

Non-statistically obtained images A, B, C were found to further decrease the expression of MAP2 meaning that the higher the dose of amlodipine will reduce the expression of MAP2 in the $50 \mathrm{mM}$ hyperglycemia neuron culture on the sixth day. 
Table I. Normality Test Results for MAP2 Expression

\begin{tabular}{|l|c|}
\hline \multicolumn{1}{|c|}{ Group } & p-value \\
\hline Glucose $50 \mathrm{mM}$ & 0.145 \\
\hline Glucose $50 \mathrm{mM}+$ Amlodipine $10 \mathrm{nM}$ & 0.833 \\
\hline Glucose $50 \mathrm{mM}+$ Amlodipine $100 \mathrm{nM}$ & 0.082 \\
\hline
\end{tabular}

Note: If $\mathrm{p}$-value $<0.05$ means the data is not normally distributed and if $\mathrm{p}$-value $>0.05$ means the data is normally distributed.

Result in table I, MAP2 data for each observation group has shown p-values that are all greater than 0.05. So all data has been proven to be normally distributed so that the parametric prerequisite tests are met.

Table II. Results of ANOVA MAP2 Test Results

\begin{tabular}{|c|c|}
\hline Variable & p-value \\
\hline Glucose $50 \mathrm{mM}$ & 0.082 \\
\hline
\end{tabular}

Note: If p-value $<0.05$ means the data is not normally distributed and if p-value $>0.05$ means the data is normally distributed.

The results in table II show that the ANOVA test results showed that there were no significant differences between the three groups. This means that when the $50 \mathrm{mM}$ hyperglycemia neuron culture in the sixth day is given amlodipin dose of $10 \mathrm{nM}, 100 \mathrm{nM}$, and without amlodipine administration does not show a statistically significant difference in MAP2.

Table III. Spearman Correlation Test Results

\begin{tabular}{|c|c|c|}
\hline Variable & p-value & Correlation coefficient \\
\hline Glucose $50 \mathrm{mM}$ & 0.011 & -0.791 \\
\hline
\end{tabular}

Table III shows the results of the significant correlation ( $\mathrm{p}$ $=0.011)$ and strong negative $(r=-0.791)$. This means that the higher the dose of amlodipine, the lower the MAP2 value.

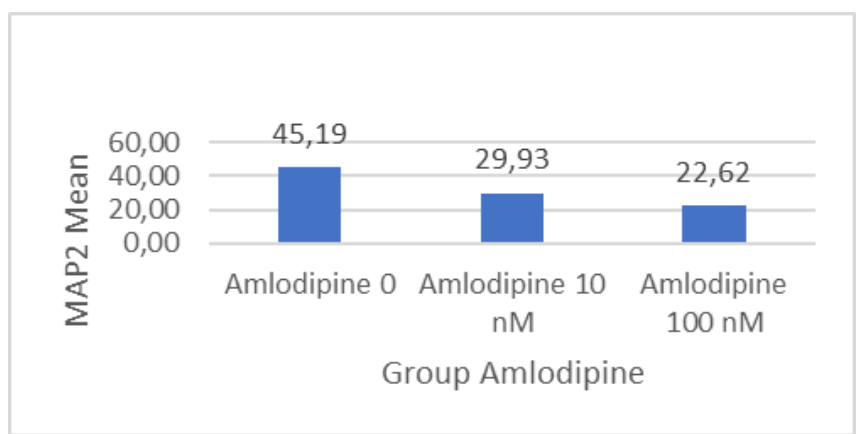

Fig. 2. Mean table of MAP2 (bytes) expression.

Figure 2 shows the average histogram of MAP2 expression in all groups, mean table of MAP2 (bytes) expression in SH-SY5Y neuron culture with amlodipine $10 \mathrm{nM}, 100 \mathrm{nM}$ and without amlodipine intervention. It was shown that the average expression of MAP2 is decreasing.

\section{B. Factors That Affect MAP2 Expression}

Amlodipine administration at doses of $10 \mathrm{nM}$ and $100 \mathrm{nM}$ which were $50 \mathrm{mM}$ glucose induced in SH-SY5Y neuron culture showed a decrease in MAP2 expression but was not statistically significant. This is demonstrated through the results of observations using examinations with immunofluorescence methods which show the least expression of MAP2 that is seen. The mechanism of the decline of MAP2 in SH-SY5Y cells is the administration of amlodipine which works as a calcium channel blocker in LTCC receptors (L-Type Calcium Channel) in neuron cells capable of lowering intracellular $\mathrm{Ca}^{2+}$ ions.

Treatment after being given amlodipine $10 \mathrm{nM}$ and 100 $\mathrm{nM}$, the results of MAP2 expression were lower than those without amlodipine. This is because the administration of amlodipine at 10 and $100 \mathrm{nM}$ further decreases the expression of MAP2 and will activate other pathways. This is in accordance with research according to Ahluwalia, which is a decrease in intracellular $\mathrm{Ca}^{2+}$ ions will reduce the activation of calmodulin-dependent protein kinase (CaMK) causing phosphorylated MAP2 to decrease due to fewer antibodies attached to MAP2. Decreased MAP2 phosphorylation will reduce MAP2 seen from immunofluorescence [15].

There is another activation that causes a decrease in MAP2, according to Hoskison in 2007 that activation of the N-Methyl-d-aspartic acid (NMDA) receptor will inhibit the potential for post synapse and increase the activation of calpain causing a decrease in MAP2. Besides NMDA receptor activation, there is also activation of calmodulin-dependent protein phosphatase 2B (calcineurin) which decreases MAP2 phosphorylation which causes MAP2 to decrease [16]. Amlodipine administration at a dose of $10 \mathrm{nM}$ at $50 \mathrm{nM}$ glucose induction increased MAP2 expression more than $100 \mathrm{nM}$. This is thought to be because amlodipine has an effect against MAP2 through the amount of dosing.

In a study according to Leeds giving amlodipine at a dose of $10 \mathrm{nM}$ and $100 \mathrm{nM}$ in cerebellum granular cell culture showed better cell viability on giving amlodipine at a dose of $10 \mathrm{nM}$. This is because giving amlodipine at a dose of 100 $\mathrm{nM}$ will increase depolarization of cells through glutamate so that it activates the NMDA receptor (N-Methyl-D-Aspartate) which is exotoxicity to cells through its role in reducing phosphorylation of MAP2 and activation of the nitric oxide synthase enzyme so that it occurs decreased MAP2 expression and increased apoptotic processes of cells [14].

\section{Research Limitations}

In this study the sample obtained was less than the sample size calculated using the Federer sample size formula. In calculating the sample size obtained the sample size required in this study amounted to 9 . In this study using 3 samples in each group measured this will affect the significance of the statistical tests conducted. Adequate sample size is essential to achieve high statistical power results. Low statistical power is often in line with inadequate sample sizes [17].

\section{CONCLUSION}

Amlodipine dose of $10 \mathrm{nM}$ and $100 \mathrm{nM}$ in the culture of SH-SY5Y neurons induced by chronic hyperglycemia (glucose $50 \mathrm{mM}$ ) could not show an increase in MAP2 expression. Different amlodipine doses cannot show differences in the increase in MAP2 expression. Amlodipine administration cannot show the increase in

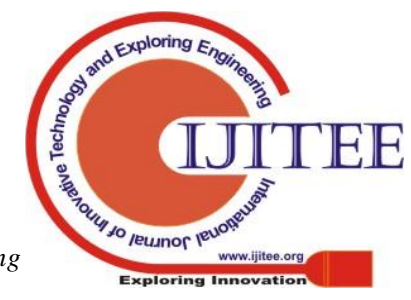




\section{Effect of Amlodipine to MAP2 on Neurons Culture SH-SY5Y That Induced by Chronic Hyperglycemia}

MAP2 expression, the possibility of other factors such as activation of other pathways, namely through the presence of NMDA and calcineurin in neurons after amlodipine administration and the number of study samples is lacking.

\section{ACKNOWLEDGMENT}

This research was carried out with the financial support of BPPM (Agency for Research and Community Service) Faculty of Medicine, Brawijaya University, Malang, Indonesia.

\section{REFERENCES}

1. American Diabetes Association, Diagnosis and Classification of Diabetes, Diabetes Care, 2014, 37, Supplement 1, pp. S81-S90.

2. Badrul M., Harun A. R., Rizky R., Relationship between the random blood glucose levels during admission at emergency room with clinical output in acute ischemic stroke patients, Malang Neurology Journal, 2015, 1, 2, pp. $52-60$

3. Shaw, J.E., Sicree, R.A., Zimmet, P.Z., Global estimates of the prevalence of diabetes for 2010 and 2030, Diabetes Res. Clin. Pr., 2010, 87, 1, pp. 4-14.

4. Bethasiwi P., V. L. Anggraini, M. D. Pratiwi, M. Husna, S. N. Kurniawan, Diagnostic Test of Toronto and Modified Toronto Scoring, Monofilament Test, and Vibrate Sensation Test Using $128 \mathrm{~Hz}$ Tuning Fork for Diabetic Polyneuropathy, Malang Neurology Journal, 2018, 4, 1, pp. 25-34.

5. Zhang, J., Dong, X.P., Dysfunction of microtubule-associated proteins of MAP2/tau family in prion disease, Prion, 2012, 6, 4, 334-338

6. Kurniawan S. N., Intracellular $\mathrm{Ca}^{2+}$ Homeostasis, Malang Neurology Journal, 2015, 1, 1, pp. 36-45.

7. Rania A. M., Diana L., Imam S., Effect of alpha lipoic acid on MDA levels and histology of brain in type 1 DM, Malang Neurology Journal, 2017, 3, 1, pp. 23-29.

8. Yamagata, K., Ichinose, S., Tagami, M., Amlodipine and carvedilol prevent cytotoxicity in cortical neurons isolated from stroke-prone spontaneously hypertensive rats, Hypertension Research, 2004, 27, 4, pp. 271-282.

9. Agholme, L., Lindström, T., Kgedal, K., Marcusson, J., Hallbeck, M., An in vitro model for neuroscience: Differentiation of SH-SY5Y cells into cells with morphological and biochemical characteristics of mature neurons, Journal of Alzheimer's Disease, 2010, 20, 4, pp. 1069-1082.

10. Kovalevich, J., Langford, D., Considerations for the use of SH-SY5Y neuroblastoma cells in neurobiology, Methods in Molecular Biology, 2013, 1078, pp. 9-21.

11. Newcomb-Fernandez, J.K., Zhao, X., Pike, B.R., Wang, K.K.W., Kampfl, A., Beer, R., DeFord, S.M., Hayes, R.L., Concurrent assessment of calpain and caspase-3 activation after oxygen-glucose deprivation in primary septo-hippocampal cultures, Journal of Cerebral Blood Flow and Metabolism, 2001, 21, 11, pp. 1281-1294.

12. Dudek, S.M., Fields, R.D., Mitogen-activated protein kinase/extracellular signal-regulated kinase activation in somatodendritic compartments: roles of action potentials, frequency, and mode of calcium entry., The Journal of Neuroscience : The Official Journal of the Society for Neuroscience, 2001, 21, 2, pp. RC122.

13. Zhang, X.P., Kit, E.L., Mital, S., Chahwala, S., Hintze, T.H., Paradoxical release of nitric oxide by an L-type calcium channel antagonist, the R+ enantiomer of amlodipine, Journal of Cardiovascular Pharmacology, 2002, 39, 2, pp. 208-214.

14. Mason, R.P., Leeds, P.R., Jacob, R.F., Hough, C.J., Zhang, K.G., Mason, P.E., Chuang, D.M., Inhibition of excessive neuronal apoptosis by the calcium antagonist amlodipine and antioxidants in cerebellar granule cells, Journal of Neurochemistry, 72, 4, 1448-1456

15. Ahluwalia, B., 2000, Low Levels of Ethanol Stimulate and High Levels Decrease Phosphorylation in Microtubule-Associated Proteins in Rat Brain: an in Vitro Study, Alcohol and Alcoholism, 1999, 35, 5, pp. $452-457$.

16. Hoskison, M.M., Yanagawa, Y., Obata, K., Shuttleworth, C.W., Calcium-dependent NMDA-induced dendritic injury and MAP2 loss in acute hippocampal slices, Neuroscience, 2007, 145, 1, pp. 66-79.

17. Dumičić, K., Žmuk, B., Use of power of analysis in choosing appropriate sample size for quality inspection, Poslovna Izvrsnost Zagreb, 2013, VII, 1, pp. 147-160.

\section{AUTHORS PROFILE}

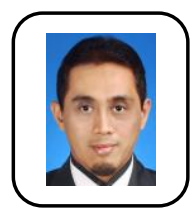

Shahdevi N. K, is $\mathrm{PhD}$ in neurophysiology, Neurology Department, Medical Faculty of Brawijaya University, Malang, Indonesia.

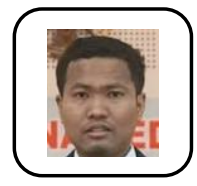

Pratama F. A, is student at Medical Faculty of Brawijaya University, Malang, Indonesia.

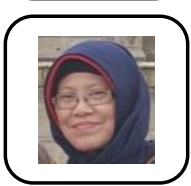

Masruroh R, is PhD in biomedical science at Neurology Department, Medical Faculty of Brawijaya University, Malang, Indonesia.

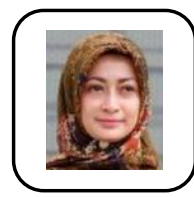

Dessika R, is neurooncologist at Neurology Department, Medical Faculty of Brawijaya University, Malang, Indonesia. 